\title{
Neurology and clinical neurophysiology: an artificial divide
}

\author{
Matthew C Kiernan (D) 1,2
}

${ }^{1}$ Brain and Mind Centre, The University of Sydney, Sydney, New South Wales, Australia ${ }^{2}$ Department of Neurology, Royal Prince Alfred Hospital, Sydney, New South Wales, Australia

\section{Correspondence to} Professor Matthew C Kiernan, Brain and Mind Centre, The University of Sydney, Sydney, New South Wales, Australia; matthew.kiernan@sydney. edu.au

Accepted 5 April 2021 Published Online First 28 April 2021

\section{Check for updates}

(c) Author(s) (or their employer(s)) 2021. No commercial re-use. See rights and permissions. Published by BMJ.

To cite: Kiernan MC. Pract Neurol 2021;21:274275.
The editors of Practical Neurology ask a reasonable question: who is best placed to oversee the neurophysiological investigation of patients presenting with neurological symptoms? Before considering the complexities of this seemingly straightforward question, it is accepted at the outset that any physician or technician could be trained to follow a testing proforma based on a symptom, or constellation of symptoms. So, the question does not relate to an issue of capability, nor should it relate to capacity. Rather, it would seem logical to consider how the best outcome can be achieved-that is, to diagnose the cause that underlies a patient's symptoms.

Clinical neurophysiology forms part of a neurologist's array of instruments and tests that, carefully coordinated, yields the most rewarding and sometimes surprising results. At its simplest level, it represents a technology platform that aids the diagnosis and management of patients with neurological disease. More fundamentally, however, it is indispensable for differentiating myopathic from neuropathic causes of weakness; and for determining the pattern of neurogenic abnormality. ${ }^{1}$ Critically, clinical neurophysiology can assist in the diagnosis and localisation of a lesion, and in staging the development or recovery from neurological diseases. In the presence of neurogenic abnormalities, electromyography (EMG) studies can reveal changes of denervation that are not apparent or not definite by means of clinical examination..$^{2-4}$ As such, the EMG machine can be considered akin to an electrical stethoscope: it enables the neurologist to detect clinical signs that often cannot be identified by clinical examination. What it reveals and subsequently achieves for each patient will vary, even when the pathological condition is the same, depending on that particular patient's clinical symptoms and signs. In this setting, it could be suggested that neurophysiological testing should be undertaken by someone who not only understands the patient's neurological presentation, but who can determine what is to be studied as the test is being performed, and who can interpret the findings in situ and in relation to the patient's clinical presentation and phenotype.

Before considering the more complex answer to the original question, we must agree that whoever undertakes the testing should be sufficiently trained and have appropriate experience with the testing apparatus and techniques. Essentially, that means dedicated training (fellowship) and supervision, followed by a period of transition from trainee to accredited service provider. In many countries, neurophysiological testing is undertaken by neurologists. In others, particularly in Europe, training in clinical neurophysiology and the provision of electrodiagnostic services has branched off to become a standalone specialty, separate to neurology. The potential benefits of this approach include a review by a second set of eyes, an increase in practice within the specific area, and the saving of time.

In the standalone model, after a consultation with a neurologist, the patient presenting with limb weakness would receive a referral to a new specialist to undertake diagnostic neurophysiological testing. In such a setting, it is accepted that many of the subtleties garnered through the clinical history and examination (as undertaken by the now referring neurologist) would largely fall by the wayside. Having received a referral, the clinical neurophysiologist would then develop their perspective on the presentation, to determine a process of testing that would aid the diagnosis of the patient's condition. These simple acts of process segregation serve no real purpose, other than being service (specialty) driven, and 
certainly provide no added benefit for the patient. On the contrary, there remains potential for a relatively simple process to be subjugated, with the possibility that the clinical neurophysiologist embarks on a course of testing that may not answer the question posed by the referring neurologist-namely, what is the cause of the patient's weakness?-which becomes lost in translation. Furthermore, the clinical neurophysiologist remains separated from the process, and is not responsible for subsequent treatment and patient management.

Of course, with any service, there are inevitable issues related to supply and demand, and indeed financial considerations. ${ }^{5}$ However, such matters should not be the core consideration when asking who is best placed to undertake the neurophysiological testing of patients presenting with neurological problems. From an historical perspective, neurophysiology from its inception has been intimately linked to neurology, and particularly neurological discovery. Over more recent decades, it has been the key pathway to unlock patient symptomatology and, in many cases, the clinical phenotype. Perhaps this mutually dependent relationship was best described by EA Carmichael through his guiding philosophy that the best way to study neurological disease was to study human physiology. ${ }^{6}$ While the use of technology has permeated all subspecialty endeavours-from neurogenetics through to neuroimaging-the key contributions of clinical neurophysiology have been increasingly hardwired into the modern-day practice of neurology. By analogy, one could also reasonably ask why neurologists do not report brain scans. In consort, the landscape is rapidly changing, and taking the field of stroke neurology and endovascular clot retrieval as cases in point, this change has already occurred, with neurologists reporting scans of their patients, as well as the intervention. Would this report be better coming from a radiologist, divorced from the patient, the clinical presentation, the intervention and the outcome?
Taken from a different perspective, were you to ask aspiring neurologists as to their preference-undertake their own neurophysiological testing, or outsource it to a separate craft group-I would venture to guess that those with a relevant subspecialty interest, where neurophysiological testing forms part of standard patient diagnostic workup and monitoring, would ask to turn on the power, activate their electrical stethoscopes and listen to the music.

Twitter Matthew C Kiernan@JNNP_BMJ

Contributors MCK is the sole author.

Funding This study was funded by National Health and Medical Research Council of Australia Programme Grant (\#1132524), Partnership Project (1153439) and Practitioner Fellowship (1156093).

Competing interests MCK serves as Editor-in-Chief of the Journal of Neurology, Neurosurgery \& Psychiatry (BMJ, UK).

Patient consent for publication Not required.

Provenance and peer review Commissioned; externally peer reviewed by Nick Kane, Bristol, UK.

ORCID ID

Matthew C Kiernan http://orcid.org/0000-0001-9054-026X

\section{REFERENCES}

1 Rubin DI. Needle electromyography: basic concepts. Handb Clin Neurol 2019;160:243-56.

2 Shefner JM, Al-Chalabi A, Baker MR, et al. A proposal for new diagnostic criteria for ALS. Clin Neurophysiol 2020;131:1975-8.

3 Yeh WZ, Dyck PJ, van den Berg LH, et al. Multifocal motor neuropathy: controversies and priorities. J Neurol Neurosurg Psychiatry 2020;91:140-8.

4 Garg N, Park SB, Vucic S, et al. Differentiating lower motor neuron syndromes. J Neurol Neurosurg Psychiatry 2017;88:474-83.

5 Nuwer MR, Duncan M, Nuwer JM. A profile of Neurology practice based on Medicare services: an AAN medical economics and management Committee report. American Academy of Neurology. Neurology 2001;56:586-91.

6 Merton PA. The first Carmichael memorial lecture. neurophysiology on man. J Neurol Neurosurg Psychiatry 1981;44:861-70. 